\title{
Others and Imagination in Reasoning and Argumentation: Improving our Critical Creative Capacity
}

\author{
Michael D. BAuMtrog
}

ArgLab, IFILNOVA. Faculdade de Ciências Sociais e Humanas

Universidade Nova de Lisboa

Avenida de Berna 26, 1069-061

Lisbon, Portugal

baumtrog@fcsh.unl.pt

\begin{abstract}
Contemporary theories highlight the importance of Others for an individual's reasoning and/or argumentation. Reasoners and arguers are encouraged to interact with imagined constructs or with other people, which are meant to bring to mind overlooked reasons and counter-considerations so as to improve the quality of reasoning or argumentations. But this advice ignores the impact of differing individual's imaginative abilities, while consulting other people comes with its own serious limitations. Reasoners and arguers would do just as well to improve their own critical creative capacities first.
\end{abstract}

Résumé: Les théories contemporaines soulignent l'importance des autres pour que nous puissions bien raisonner et argumenter. Afin d'améliorer la qualité de nos raisonnements et de nos arguments, nous sommes encouragés à interagir avec des constructions imaginées ou avec des personnes qui ont pour but d'avancer les raisons et les contreconsidérations que nous négligeons dans nos raisonnements et dans nos arguments. Mais ce conseil ignore l'influence de nos différentes capacités d'imagination et les limites sérieuses dans la consultation des autres. Nous ferions tout aussi bien d'améliorer nos propres capacités créatives critiques.

Keywords: imagination, reasoning, argumentation, critical thinking

\section{Introduction}

This paper is concerned with the creation of considerations and counter-considerations (reasons) in reasoning and argumentation. Its main purpose is to draw attention to and provide theoretical reflection on the importance of creativity $^{1}$ in reasoning

\footnotetext{
${ }^{1}$ Ken Robinson (2011) distinguishes imagination and creativity. For him, imagination is "the process of bringing to mind things that are not present to our senses" (p. 2) and creativity is described as a kind of applied imagination, a doing (p. 141-142). Although I am sympathetic to this distinction, in light of the differing uses of the terms in the other sources I draw on, it is not en-
} 
and argumentation construction and evaluation. Drawing attention to the role and influences of creativity in these instances is important for at least two reasons. First, its role seems to have been thus far underappreciated, and second, it has somewhat uncritically been assumed to be easily addressed through the inclusion of more participants in the reasoning and argumentative processes. In what follows, I argue that there are both theoretical and empirical grounds to question the common view. Especially when we have to take action and there is no one around with whom to deliberate or argue, improving our creative ability to produce reasons becomes paramount. A further benefit of improving individual creativity is that it also then improves group creativity in dialogical and polylogical situations.

The creation of reasons happens in a myriad of situations. Sometimes these are instances of explicit reason and argumentation, while others they are not. Here, I am only concerned with their role in explicit reasoning and argumentation. An effective way to assess their role in this dynamic is to review their import in the use of a model for reasoning or argumentation such as an argumentation scheme. An argumentation scheme is most often comprised of two parts - an abstract pattern of reasoning accompanied by associated critical questions. In the case of theoretical reasoning, an argumentation scheme provides the user with a conclusion to believe. Following a scheme or model of practical reasoning, provides the user with a conclusion about what to do. When conducting theoretical reasoning, an agent can hold a belief until further considerations can be brought to light that may overturn it. In the case of practical reasoning, however, the importance of imagining reasons and objections before acting is much more pressing, given that actions cannot be changed or undone after they are taken. In light of this increased importance, in what follows I focus on practical reasoning and argumentation as the standard example, and for simplicity I provide only one model, though many of the considerations to follow bear importance for reasoning and argumentation more generally, including on theoretical models and examples as well.

Walton, Reed, and Macagno articulate the argumentation scheme for value based practical reasoning as,

Premise 1: I have a goal $G$.

Premise 2: $G$ is supported by my set of values, $V$.

Premise 3: Bringing about $A$ is necessary (or sufficient) for me to bring about $G$.

forced here. For present purposes the terms can be taken broadly and as synonymous. 
Conclusion: Therefore, I should (practically ought to) bring about $A$.

\section{Critical Questions}

CQ1: What other goals do I have that might conflict with $G$ ?

CQ2: How well is $G$ supported by (or at least consistent with) my values $V$ ?

CQ3: What alternative actions to my bringing about $A$ that would also bring about $G$ should be considered?

CQ4: Among bringing about $A$ and these alternative actions, which is arguably the best of the whole set, in light of considerations of efficiency in bringing about $G$ ?

CQ5: Among bringing about $A$ and these alternative actions, which is arguably the best of the whole set, in light of my values $V$ ?

CQ6: What grounds are there for arguing that it is practically possible for me to bring about $A$ ?

CQ7: What consequences of my bringing about $A$ that might have even greater negative value than the positive value of $G$ should be taken into account? (2008, p. 324)

One role of the pattern of reasoning is to guide the user to a reasonable conclusion. But, in many cases the reasonableness of the pattern of reasoning is defeasible, as this one is. ${ }^{2}$ As such, the associated critical questions are meant to address potentially troublesome aspects that could weaken the reasonableness of the reasoning and/or its conclusion. As contemporary thinking has it, if a user follows the pattern of reasoning and satisfactorily addresses the associated critical questions, then, all things being equal, the conclusion can be considered reasonable.

As has been pointed out, however, individuals have limited imaginations (Johnson 2000). If these limitations differ from person to person, it could mean that some people are better able to make use of argumentation schemes than others. In order to compensate for the potential lack of an individual reasoner's imaginative abilities, many argumentation theorists suggest relying on another interlocutor (Johnson 2000; van Eemeren \& Grootendorst 2004; van Eemeren 2010; Tindale 1999, 2004).

Although the assumption has generally been that another interlocutor can act as both a contributor to and safeguard of

\footnotetext{
${ }^{2}$ This defeasibility can also be the determining factor between reasonable and fallacious uses of an argumentation scheme. For example, see Bondy (2015) for a useful discussion of this phenomenon as it applies to ad hominem argumentation. See Walton (2010) for discussion of reasonable use of $a d$ vericudium and ad ignorantium.
} 
reasoning and argumentation, recent empirical research has provided reason to reinvestigate this assumption. Moreover, there are many situations where an independent interlocutor is not available for consult and a reasoner is left to her or his own devices. In such situations, improving the creative abilities of each individual becomes of paramount importance.

As such, the aim of the paper is to argue for increased attention to the importance of individual creative ability in reasoning and argumentation construction and evaluation. The overarching idea is that improving the likelihood of a reasonable conclusion depends on at least two interrelated factors: (1) the quality of the normative scheme/model and (2) the abilities of the agent(s) using the model. To use an analogy, just as a good quality hammer may make nailing a piece of wood easier, if the user of the hammer taps the nail lightly 15 times instead of hitting it hard twice, no matter how well the hammer has been constructed, it will not perform as well as it could. This is not to underplay the importance of the quality of the tool. A hammer will most often perform better than a shoe in the same task. The point is just that, as with any tool, whether used in reasoning and argumentation or carpentry, there is a reciprocal relationship between the tool and its user and best results are incurred when both are improved. Our focus here is on the user.

Accordingly, the paper begins by addressing how individuals, despite the quality of the design of a model, may use it poorly. We then move on to address the most common theoretical approach to overcoming what can be called "the imagination problem." namely, appealing to an imagined Other or group of Others. Section four discusses some of the limitations of real others and argues that although in some cases the reliance on an Other can be beneficial, the strategy remains ultimately unsatisfying. Finally, section five looks to work done in critical thinking for a solution, out of which the concept of an individual's critical creative capacity is introduced as a target to aim at for improving individual argumentative creativity and subsequently argumentative products.

\section{Individuals}

It is no secret that individuals err in their reasoning. The influential line of research on cognitive biases and heuristics has powerfully demonstrated that even the most intelligent people, without corrective interference (and sometimes even with), tend to conduct their reasoning and argumentation in predictably biased 
ways (Kahneman 2011, p. 234ff; Kenyon \& Beaulac 2014). For example, consider the long established availability heuristic (Tversky and Kahneman 1973; 1974, pp. 1127-8). The availability heuristic identifies people's tendency to reason using information that is most readily available to them. In 'Western' society, mass media are responsible for much of this selection. How the information comes to the information user is also important - the more salient, the more likely the information is to be recalled first. Seeing a terrorist attack or an earthquake on TV will have a greater effect than reading about it in the newspaper (Sunstein and Hastie 2015, p. 45). As Chappell (2011, p. 94) explains, one can identify "a bias towards vivid arguments that consist of imagery that is easy to understand and assigns causality to specific actors when the true state of the world is best described by opaque arguments, which are difficult to understand and make use of invisible hand mechanisms". Thus, if information is readily available, simple, and salient, it is more likely to be recalled first and provided a heavier weight - appropriately or not.

We can also consider the planning fallacy, which is especially important for practical reasoning given that one of the most famous, influential, and well-articulated theories of practical reasoning is called the "the planning theory" (Bratman 1987). The planning fallacy describes the tendency to produce plans and forecasts that are "unrealistically close to best case scenarios [and/or] could be improved by consulting the statistics of similar cases" (Kahneman 2011, p. 250). As Sunstein and Hastie (2015, p. 139) describe it, "[t]he planning fallacy is a form of myopia, focusing on one streamlined scenario". Such myopic thinking has the consequence of leaving relevant counter considerations unconsidered and/or underappreciated.

Unfortunately, as of yet there is no way to prevent these (and other) biases from impacting practical reasoning. Indeed, in part because of the availability bias, when conducting practical reasoning an agent is unlikely to consider all (or the best) options for use in the pattern or reasoning. She may also overlook or downplay important responses to the associated critical questions because of an over optimism stemming from the planning fallacy.

In some cases, methods have been found which assist in "de-biasing"3 and not all biases are related to imaginative ability. I mention only these two examples as illustrations of how

\footnotetext{
${ }^{3}$ See Kenyon \& Beaulac (2014) for a useful overview and discussion of contemporary debiasing techniques including some examples of cases where debaising efforts have been shown to make things worse.
} 
individuals can be seen to err, or at least underperform, due to limited imaginative or critical creative capacity. There is no consensus as of yet on a best way to conduct effective debiasing exercises (Kenyon \& Beaulac 2014) but that research is a welcome partner to this research. As a philosophical paper, the focus here is on questioning the theoretical underpinnings of argumentation theories that place great emphasis on the role of the Other as guardian against biases like the two mentioned above.

It is often thought that one way to help counter individual errors in reasoning and argumentation is to submit it to an interlocutor-to an "Other". This Other will help alert us to the mistakes we are making that we cannot see ourselves. As Johnson (2000, p. 158) has argued, "it does not matter how fertile imaginations are; there will be objections that cannot be imagined or anticipated. These are the limitations for which the Other can compensate". The Other, then, can be seen to be of assistance in at least two ways: to critically test the available reasoning and argumentation as well as to contribute to it imaginatively.

There is no doubt that an Other can fulfil this role, but can every Other do so? If not, what might make one Other better or worse than another? Further if an Other is helpful, would more than one Other be even more helpful? Finally, what are we to do

if there is no Other around but a decision still has to be made? The remainder of the paper addresses these questions.

\section{Theoretically better others}

Granting that individuals have limited imaginative capacity, we can now review the theoretical suggestions from argumentation theory aimed at addressing this deficiency-imagining engaging some sort of interlocutor, some kind of Other. Two of the most recognizable characterizations of theoretically best interlocutors are Perelman and Olbrechts-Tyteca's universal audience and Blair and Johnson's community of model interlocutors.

For Perelman and Olbrechts-Tyteca (1969, pp. 30-35, 6673 ), argumentation is always aimed at a real audience. Given, however, the varying compositions of real audience members, along with their fallibilities, they develop the hypothetical "universal audience" which can be imagined out of the real audience. The motivation for creating the universal audience is to avert an arguer relying "on arguments that are foreign or even directly opposed to what is acceptable to persons other than those he is presently addressing" (p. 35). As an extrapolation from a real audience, the universal audience is a hypothetical but 
not an ideal (Tindale 2004, p. 128). The universal audience is "the distillation of the concrete audience, comprised of the common features as imagined by the arguer (speaker)" (Tindale 1999, p. 90) since "[e]veryone constitutes the universal audience from what he knows of his fellow men, in such a way as to transcend the few oppositions he is aware of' (Perelman and Olbrechts-Tyteca 1969 , p. 33). In this way, the universal audience remains grounded in reality. The point of imagining a universal audience is to bring to mind stronger reasons, considerations, and argument than would have been conceived otherwise.

There are different ways for an arguer to construct the universal audience. As mentioned, the arguer can identify the common features of the particular audience, but they can also select the most reasonable elements among the members and universalize them, or imagine the audience across vast distances of time. Along with their unique individual characteristics, the members of the audience are conceived of as reasonable and thus when universalized, embody reasonableness as a standard. Accordingly, the premises of any argument should be universalizable, without contradiction, to all members of the universal audience (Perelman, 1982, p. 18). Thus, once constructed, the universal audience can then perform at least three functions: they can be question askers, perspective providers, and reasonableness developers (Tindale 1999, pp. 119-120).

A related, but noticeably different approach is taken by Blair and Johnson (1987) who propose the idea of a community of model interlocutors. This community is characterized as (at least) knowledgeable, reflective, open, and dialectally astute (pp. 50-51). Their knowledge is associated with them as a community of experts whose composition changes, but nevertheless all embody the ideal of reasonableness. They are not, however, the final source of knowledge - a place to find all the answers. Rather they are open to changing their opinion based on reasons. Since they are dialectically astute, the community are comfortable with argumentation and are "alert to possible problems of relevance, to the need for enough evidence of the right kinds, and to the possibilities of counter arguments and conflicting evidence" (p. 51).

Blair and Johnson also point to five features of the community's operation. First, there is a particular group for each proposition. Second, "[t]he membership of the community of model interlocutors will vary from proposition to proposition" (ibid.). Third, the members would be real people-role models - with high but attainable standards. Fourth, it is a collection of role models, rather than an individual. Finally, fifth, the role 
models are recognized as in a historical place in time, rather than being universal.

There is not space or need here for a full comparison between the two views. ${ }^{4}$ The point I most want to highlight is the requirement for the use of imagination in both cases. In the case of the universal audience, it is up to the arguer to construct/imagine/create the universal audience in their mind. Such imagination is constrained in this case by the actual audience to which the argumentation is addressed (Tindale 2004, p. 140). But since there are a number of ways to go about constructing the universal audience (generalizing, universalizing, etc.), the arguer's imagination still plays a central role. In the case of the community of model interlocutors, Blair and Johnson (1987) write, "[w]e wish to advance the hypothesis that in the paradigmatic case of argumentation, those occupying the two dialectical roles conceive themselves as trying to satisfy the demands of a community of interlocutors characterized by features which establish certain standards of objectivity as a goal in the argumentative interchange" (p. 50). In this case too the arguer(s) are asked to imagine a model community with exceptional demands on argumentative practice. To be clear, since such a community is a model, the expectation is not that any given arguer is actually arguing with this community (even if in fact they do exist in the world), but that they remain an imaginative construction based on real existing experts.

One way to highlight the way I see the importance of imagination as entering into these two situations is to think about the prospect that two real arguers, faced with the same real audience and wanting to make the same point, would imagine an identical universal audience or community of model interlocutors. Though an empirical question, I think it is uncontroversial to posit that if they would not construct the exact same audience, then we have a clear indication that their respective imaginative abilities come into play. As such, an arguer's imaginative ability will be crucial for both the production of their own quality argumentation as well as the evaluation of others'. Tindale (2004, p. 112) says as much when he asserts, "[t]he ability to imagine counterarguments is synonymous with the ability to evaluate one's own arguments" (see Mizrahi 2014). If the source of the imagined counter arguments comes from an imagined universal audience or model community, then the ability to evaluate one's own arguments is synonymous with the ability to imagine such an audience or community. Further, if any two arguers are un-

${ }^{4}$ For some comparative insights, see Tindale (1999, pp. 115-117; 2004; 127, 128). 
likely to create identical audiences they are unlikely to provide the same quality argumentation and/or evaluation-the more imaginative one will do better. Thus, improving the imaginative ability of an arguer is one of the most crucial aspects to improving the quality of argumentation. Unfortunately, however, it seems to be one of the least discussed.

\section{Empirically better others}

Aside from these theoretical constructs, recent research has investigated who makes for better or worse interlocutors in the real world. Sunstein and Hastie (2015), based on Sunstein's real world experience working in the White House, but also congruent with their extensive scientific research, distinguish between complacent and anxious leaders (though the more general "decision maker" could easily replace "leader"). Complacent leaders, "are full of energy, excitement, enthusiasm, and optimism" (Sunstein \& Hastie 2015, p. 10). Although complacent leaders are often full of good ideas, they are also more prone to be overconfident in those ideas and prefer "happy talk" to "rocking the boat". Anxious leaders, on the other hand, "may be optimistic, nice, even enthusiastic and full of smiles, but they are also troubled by concern, skepticism, and doubt [...they...] see obstacles, downsides, and challenges everywhere" (pp. 10-11). Anxious leaders "ask probing questions along the lines of, "what could go wrong? Did you think of this? Why haven't you planned for that?"' (p. 11). In other words, anxious leaders are critical and Sunstein and Hastie are unequivocal in promoting anxious leaders as better interlocutors for decision-making.

Such findings are also congruent with a study conducted by Schulz-Hardt, Jochims, and Frey (2002; Schulz-Hardt et al. 2006), which found that disagreement between interlocutors counteracted the confirmation bias and contributed to improved information seeking, which helps counter the availability bias. Most interestingly, they also found a difference between genuine and contrived dissent. Information seeking improved more in situations of genuine dissent than when in a situation of devil's advocate, though importantly, both were effective in countering the confirmation bias.

A common theme between the theoretical and empirical work is one of character, rather than ability. The best Others with whom to conduct practical reasoning and argumentation need to disagree with you. What are needed are dissent, skepticism, and challenge. This may sound like somewhat of an obvi- 
ous point, but as will be discussed below it is far from a standard situation. Social dynamics may silence dissent on both epistemic and non-epistemic grounds, not to mention the possibility of a mere lack of motivation to use a critical imagination. Further, arguers with similar stocks of shared knowledge, or similar "cognitive environments" (Tindale 2004) may not be able to disagree with each other as readily as others. Accordingly, even a group of highly skilled argumentation and/or critical thinking scholars could find themselves debilitated by agreement. In sum, whether by yourself or imagining another, whoever it might be, a critical intent is one crucial component to improved argumentation.

\section{The more the merrier?}

If one Other can help improve reasoning, does more than one help even more? Going back to the ideas of the universal audience and community of model interlocutors, just by their names alone we can see an ingrained notion that the more interlocutors the better. Universal, meaning "all to whom the argument applies or could ever apply" would only ever in very rare cases be isolated to one individual. Also, recall from above that Blair and Johnson (1987) explicitly call for more than one individual: "We emphasize the collective nature of the norm we are proposing by speaking of a 'community' and not of an ideal individual. The point is that the ideal of argumentation conceives of a range of critical questions and a variety of critical points of view as needing responses" (p. 52). The theoretical assumption is that more people provide more imagination and corrective ability.

Although it seems to make sense that the more people with whom argumentation is exchanged the better, this is not always the case. The results from empirical studies can be said to answer the hypothetical question "Do more participants in decision making procedures produce better results?" with a resoundingly hesitant "Sometimes". Indeed, Sunstein and Hastie (2015) have pointed out a number of ways in which groups can negatively affect argumentation and decision-making. Groups can amplify errors, meaning that they can encourage each other to increase commitment to a poor decision even in the face of evidence that it is failing (p. 52). They can be subject to a cascade, which means being influenced by the choices others have made before them on the same question (pp. 57ff). They can become more polarized than before discussion began, defeating the purpose of discussion (pp. 78ff). Most interestingly, groups are 
also more likely to emphasize information that is broadly shared rather than emphasize the information most important to making the best decision (pp. 89ff), i.e., they are more likely to be cooperative than critical. ${ }^{5}$

Despite these serious problems, groups do not always make worse decisions. Sunstein and Hastie (2015) are also clear that "[f]or some biases, groups repeat the individual error but do not increase it, and for others they might even decrease it. Compared with individuals, groups have been found to demonstrate a slightly lower lever of reliance on the availability heuristic [...] And people's tendency to anchor on salient numbers ('anchoring bias') is somewhat reduced by group deliberation as are the hindsight and egocentric biases" (p. 53). The general motto they use for predicting the quality of group decisions is "garbage in, garbage out". The motto points out that if individual members are poor decision makers, the group will likely follow suit.

Of course, even if many members of the group might embody a certain bias that negatively affects the group, it does not mean that every member does. One might think that the individual group member with the correction would stop the group from falling victim to the bias. Such corrective behaviour is rarer than not, however, for at least two reasons. The first is epistemological. Using the example of a firm making a decision, when opposed to the majority, the majority's “optimism might lead the firm's skeptics to silence themselves on the ground that their own judgments must be ill informed or wrong" (p. 34). When facing majority opposition, especially about factual matters, we could reasonably enough suspect that it might be we who are wrong and thus not raise (or press) any opposition. But this situation might also occur in the face of authoritative expertise. For example, during a discussion between a student and his supervisor, the student might think the supervisor has made some sort of logical error. Since, however, the supervisor has a doctorate in logic and the student is a linguist, the student could reasonably enough suspect that his supervisor has not made a mistake, but that it is his own misunderstanding. Placing more confidence in the possibility that it is his own misunderstanding could readily prevent him from speaking up.

The supervisor example can also be used under a different light to point out the second reason for self-silencing: social incentives and the avoidance of social punishment (p. 36). If the supervisor were the kind of person who might punish her student for disagreeing or pointing out an error, say by avoiding a

\footnotetext{
${ }^{5}$ Research in deliberative democracy has also pointed out that larger groups may fail to effectively deliberate (Chappell, 2011, 2012, pp. 155ff).
} 
next meeting or delaying reading another chapter, these consequences might also cause the student to stay silent in a case where he thinks his supervisor might be making an error or overlooking an important consideration.

Thus, real Others may help reduce harmful biases and heuristics in some cases, but there is no guarantee that this will be the case. In fact, in some cases these interlocutors may actually have a negative impact on the outcome of the reasoning and argumentation. If we can not rely on Others, either real or imagined, to help improve the quality of individual reasoning and argumentation, then an alternate solution needs to be developed. In the next section I propose a theoretical target to aim at for developing such an approach.

\section{Critical thinking and the critical creative capacity}

In accordance with the "garbage in, garbage out" mentality, the idea advocated here, supported by Sustein and Hastie's research, is that improving the ability of each individual will improve the abilities of groups as well. In other words, improving an individual's ability to use an argumentation scheme will create less "garbage in" in group settings, which would in turn lead to less "garbage out" in group settings. In this way, creativity is improved in both instances of solitary and communal reasoning and argumentation. Isolated individuals will have recourse to more and better considerations and counter considerations when they are needed individually, and these individuals will bring better quality reasons to social situations.

Thus, in my view, inward focus on improving creativity is at least as important as outward focus on the abilities of others. I say, "at least" so as not to diminish the importance of creativity research in groups, but to highlight the importance of it for individuals and provide a theoretical counterpoint to the heavy reliance on Others in the theoretical argumentation literature. In other words, in addition to, and perhaps before imagining a model interlocutor or aiming at a semi-imaginary universal audience, all arguers would do just as well to improve their own critical and creative thinking skills and dispositions to come up with better reasons and answers to critical questions. The idea is that better critical thinkers will be better able to help themselves and be better able to perform as interlocutors for others. Improving this ability could indeed amount to being better able to recognize which communities of experts would be of most assis- 
tance, but this one among many results of improving creative thinking.

As such, improving individual imagination and imagining a universal audience or community of model interlocutors are not mutually exclusive. Indeed, critical and creative thinking are closely related and there is a reciprocal relationship between improving critical thinking and being able to better imagine an appropriate (group of) Other(s). I only wish to highlight the importance of independent imaginative self-improvement, which seems to be underemphasized in the theoretical argumentation literature where there is instead unequal focus on the abilities of Others. Johnson is right that no matter how fertile our imaginations are, an Other is important. But, especially in situations where there is no Other present, improving our individual abilities should be given equal importance. What then is to be improved? One answer might be "critical thinking".

\subsection{Adding 'creative' to 'critical thinking'}

Critical thinking is widely understood to involve both skills and dispositions (Siegel 1988; Tiruneh, Verburgh, \& Elen 2014; Bailin \& Siegel 2003). As Siegel (1988) argues,

[o]ne who has the critical attitude has a certain character as well as certain skills: a character which is inclined to seek, and to base judgement and action upon, reasons; which rejects partiality and arbitrariness; which is committed to the objective evaluation of relevant evidence; and which values such aspects of critical thinking as intellectual honesty, justice to evidence, sympathetic and impartial consideration of interests, objectivity, and impartiality. (p. 39 emphasis in original)

The skills component focuses on the ability to assess reasons and reasoning. It is the "ability to ascertain the goodness of candidate reasons" (Bailin \& Siegel 2003, p, 182), to "critically evaluate beliefs, their underlying assumptions, and the world views in which they are embodied" (Paul 1990, cited in Bailin \& Siegel 2003, p. 181). Thus, "[t]eaching critical thinking . . . seems to involve teaching various kinds of reflective questioning, interpretation and evaluation strategies" (Blair \& Johnson 2009, p. 3).

To teach these skills, critical thinking textbooks include discussions of argument analysis, fallacies, deductive and inductive logic, argumentation schemes, scientific reasoning, biases and debiasing, and argument diagraming - to name but only a 
few. In most recent textbooks, these skills are taught using contemporary real-world examples and illustrations. In the classroom, critical thinking instruction may occur as its own subject or be infused into a differing subject matter, or involve a mixture. ${ }^{6}$ In general, critical thinking instruction has been shown to improve students' critical thinking abilities, though differing instruction methods have differing effectiveness (Tiruneh, Verburgh, \& Elen 2014). ${ }^{7}$

Although theoretically critical thinking also has a creative component, very few textbooks address creative thinking. In Catherine Hundleby's wide-ranging database, which breaks down critical thinking textbook contents, of the 74 textbooks analyzed, only 4 textbooks fully, and 3 partially, address creative thinking. ${ }^{8}$ This demonstrates the majority focus that critical thinking instruction maintains on evaluation, rather than creation, despite the fact that one of the most well known tests for critical thinking also involves evaluating students' creative ability (Ennis \& Weir 1985, p. 1). The lack of emphasis placed on creative thinking could in part be due to some scholars holding the view that the two activities are inherently opposed. The argument is that critical thinking is focused on rules of thinking in a way that is "strictly analytic and evaluative, an algorithmic process that consists in arriving at the correct evaluation of ideas, arguments, or products," which is opposed to creative thinking, which attempts to break the rules, transcend frameworks, and create novel products (Bailin \& Siegel 2003, p. 186; Misset 2012, p. 12).

As I hope has become apparent by this point, I do not think the two types of thinking are opposed at all, but rather, are complementary. I agree with Bailin and Siegel (2003) that "[t] here are evaluative, analytic, logical, aspects to creating new ideas or products" (p. 186), and as mentioned, I see "an imaginative, constructive dimension to their assessment" (ibid.). Experts in creative thinking are also supportive of the relationship. As Robinson (2011) contends regarding creative thinking,

[c]ritics think of children running wild and knocking down furniture rather than getting on with serious work. Being creative does usually involve playing with ideas and having fun; enjoyment and imagination. But creativi-

\footnotetext{
${ }^{6}$ Ennis (1989) identifies four approaches: general, infusion, immersion, and mixed.

${ }^{7}$ The systematic review conducted by Tiruneh, Verburgh, \& Elen (2014) takes the full text of 33 empirical studies into account and for that reason I have only cited their review rather than a collection of the individual studies.

${ }^{8}$ See: http://chundleby.com/critical-thinking
} 
ty is also about working in a highly focused way on ideas and projects, crafting them into their best forms and making critical judgements along the way about which work best and why. In every discipline, creativity also draws on skill, knowledge and control. It's not only about letting go, it's also about holding on. (p. 5)

Accordingly, creative thinking can be blended with critical thinking so that both are developed as a skill and a disposition. Just like for critical thinking, there are skills and dispositions for creative thinking. It is not enough to merely know how to go about generating considerations in reasoning and argumentation; it is also valuable to have the disposition to do so whenever possible. As such, creativity can be though of a capacity, with the act of creating as its output.

As blended with critical thinking, I side with critics of creativity who argue that creativity is not some mythical creature emerging only from geniuses who make great leaps and bounds in originality (Weisberg 1986). Rather, I agree that "creating in the arts and sciences is a natural comprehensible extension and orchestration of ordinary everyday abilities of perception, understanding, memory, and so on" (Perkins 1981, p 4). In this way, creativity is seldom done in a vacuum and it should not be considered a general innate personality trait that only a select few have or that can be improved by training in how to be creative, sans context (Bailin 1988, p. 130). Tied to critical thinking, however, and purposefully aimed at the goal of improving reasoning and argumentation, I think it can be of much use.

Practically, creative thinking enhancement research has thus far mostly focused on divergent thinking (Missett 2012, pp. 9-10). Divergent thinking is listed in the Creative Encyclopedia (2009) as "cognition that leads in various directions. Some of these are conventional, and some original. Because some of the resulting ideas are original, divergent thinking represents the potential for creative thinking and problem solving" (p. 577). Unfortunately, psychological, social, and philosophical research regarding the connection between critical and creative thinking remains drastically underdeveloped (Missett, 2012; Baker et al., 2001). Independently, however, instruction in both has been shown to be effective (Karapova 2011, Tiruneh, et al. 2014; Missett 2012; Foos \& Boone 2008, Robinson 2011, Bryne 2005, pp. 181-ff). ${ }^{9}$

\footnotetext{
${ }^{9}$ There remains controversy regarding the efficacy of both critical and creative thinking instruction and I cannot here engage that debate fully. Since my focus in this paper is theoretical, I hope these supporting references provide
} 
Philosophically, if Tindale (2004, p. 112) is right and "[t]he ability to imagine counterarguments is synonymous with the ability to evaluate one's own arguments", then investigating the creation/imagination of reasons and counterarguments should be of high philosophical interest. If philosophers are the ones who declare the conditions for what is reasonable and unreasonable, they need to account for the creative/imaginative ability of the reasoner. They need to determine if an individual who makes a poor decision because of a natural (or explainable) lack of creativity should be declared unreasonable in the same way another more imaginative person could be. Further, should all individual decision-making be exempt from evaluations of reasonableness if there is no Other with whom to have it compete? These are difficult questions to answer, which would require further research. I ask them here only to highlight that the investigation of creativity and imagination has philosophical interest and should not only be relegated to the psychological domain. $^{10}$

While thinking about how to improve the user of an argumentation scheme or model, I have used a number of the considerations above to develop the concept of what I call the critical creative capacity (CCC). The idea of the CCC is not in any way meant to be a "reinvention of the wheel" of the work discussed above, but I think it organizes some areas for further research in a simple manner and focuses it in a useful way for argumentation theory. The concept is developed in the next section.

\subsection{The critical creative capacity}

United with critical thinking, improving an agent's creativity in reasoning and argumentation could take the shape of improving what I call the agent's critical creative capacity (CCC). The CCC identifies an individual's skills and dispositions to create/imagine/think up (1) the appropriate number and diversity of considerations and counter considerations; (2) which are appropriately relevant to the occurring reasoning or argumentation; while (3) attributing the appropriate role and weight to each.

at least enough reason to believe that instruction could be possible so as not to preclude the potential value of my theoretical considerations.

${ }^{10}$ For a philosophical discussion regarding the creativity as a virtue, which in many ways can be linked with virtue argumentation and other argumentative approaches, see Kieran (2014). 
The overarching ability is imaginative, but creation without constraint is chaos. ${ }^{11}$ Creativity in its argumentative and critical thinking capacity is guided by its role to come up with and scrutinize considerations for a given practical or theoretical question. Thinking of what an Other or Others might say, about the issue is one way to help the generation of considerations, but there are many, many more. ${ }^{12}$ Simply creating a large number of considerations in a vacuum is not enough, however, and the three pillars of the CCC are meant to work together to help the creativity effectively focus on its role in argumentation.

The first factor concerning the number and diversity of considerations is meant to signify that a well-functioning CCC will not needlessly dwell in or skip over an area of inquiry, but will actively seek a diversity of (counter) considerations. ${ }^{13}$ For example, imagine someone thinking about where to build a new water dam who only focuses on economic benefits and comes up with a hugely long, we might say redundant, list of them. Such an instance would be an inappropriate number of considerations that lack diversity.

The second factor, concerning relevance, helps function as a rein on the first factor. One way to ensure that we do not have too many considerations is to discard the irrelevant ones. Although the aim of keeping the considerations relevant can help avoid having too many, it cannot, however, provide advice regarding if there may be too few. This is why I have separated the first two factors.

The third factor is perhaps the hardest to work out theoretically. It involves appreciating the weight of each of the imagined, relevant, considerations. Such a stipulation is important because it is easy to miscalculate the importance of reasons we have-what should be a knockdown reason might be given too little weight, or a consideration of minor importance may appear debilitating. Thus far, however, there is no universally accepted theory regarding how to weigh reasons.

\footnotetext{
${ }^{11}$ I am inclined to agree with Blackburn's comment on a work by Goya: "Goya's full motto for his etching is, 'Imagination abandoned by reason produces impossible monsters: united with her, she is the mother of the arts and the source of her wonders,' That is how we should take it to be." (Blackburn, 1999, p. 13)

${ }^{12}$ Some paradigm examples for practical techniques to improve creative thinking in reasoning and argumentation can be found in Weston and Stoyles (2010) and DiYanni (2015). For a specific focus on groups, see Sunstein and Hastie (2015) and Paulus and Nijstad (2003).

${ }^{13}$ The focus in this article is on practically reasoning for future actions. For an invaluable discussion of imagination in counterfactual reasoning, see Bryne (2005).
} 
When in a group, a fourth characteristic becomes important: (4) the confidence to speak up and appropriately press a point. Alone, our thoughts often come to us whether we want them to or not ${ }^{14}$ and not having a thought, when explicitly attempting to reason, is a lack of creation and not generally a lack of confidence. In a group, however, as we saw above, we may have thoughts and not mention them or may let them go too early, which could negatively affect the outcome of group argumentation and decision-making. Thus, having the confidence to express oneself becomes much more important in a group than by oneself.

Before concluding, it should be noted that I am aware the articulation of the CCC bears resemblance to another well known concept from Informal Logic, the triumvirate of factors pertinent to argument evaluation proposed by Johnson and Blair (1994 p. 55ff): the argument's relevance, sufficiency, and acceptability (RSA). A few important differences, however, make the CCC worthwhile as an independent complementary concept not to be subsumed under the notion of RSA. First, while RSA concerns arguments, the CCC concerns arguers. This is most notable through the fourth $\mathrm{C}$ since an argument cannot have confidence. Relatedly, as a human capacity, the CCC is connected to both skills and dispositions as outlined by Siegel (1988). Thus, the aim is for an arguer to have both the skills and disposition to think critically and creatively. Improving an individual's CCC would increase their ability to create and critique arguments on the basis of notions like RSA - to come up with better critiques of an argument's relevance, sufficiency, and acceptability - but requiring the evaluation of an argument's RSA says nothing about improving an individual's ability to so.

\section{Conclusion}

This paper has discussed the limitations that relying on Others has for using an argumentation scheme to conduct quality reasoning and/or argumentation. Although improving the design of

\footnotetext{
${ }^{14}$ This is not to say that humans have no control over their thought process. That is a psychological topic I am unqualified to engage. Without intending to take a position on Dennett's views overall, I mean here something like the indeterminateness of his "consideration-generator". He explains, "[t]he model of decision making I am proposing, has the following feature: when we are faced with an important decision, a consideration-generator whose output is to some degree undetermined produces a series of considerations, some of which may of course be immediately rejected as irrelevant by the agent (consciously or unconsciously)" (Dennett 1978, p. 295).
} 
an argumentation scheme and its critical questions is important for improving the practice of reasoning and argumentation, it is not and cannot be sufficient. In other words, there is no (and I am doubtful there can be a) "foolproof" formulation of an argumentation scheme such that its user is forced to address all possible considerations. As such, the model maintains a reciprocal relationship with its user-a better model can help improve an agent's ability and the better the ability of the agent, the better she can use the model. Thus, improving the imaginative ability of an arguer is an important area of research for argumentation theory and critical thinking.

I have proposed that this imaginative argumentative ability be thought of as an individual's critical creative capacity. I have further suggested that improving an individual's critical creative capacity means improving her or his ability to imagine the appropriate number, of the appropriately relevant and appropriately weighted considerations and counter considerations called for in the given scheme or model. I am aware that what counts as "appropriate" needs further explanation, but I hope at this point the intuitive understanding of this notion is enough to ground the overall idea and justify further research in this regard.

I also hope to have highlighted the importance of the creative, imaginative, part of critical thinking in general. I see a foundational relationship between imagination, critical thinking, and argumentation that does not seem to have been emphasised in the literature to the degree of its importance thus far. Bailin and Siegel (2003) are right that it is tough to separate critical and creative thinking, but much more research in argumentation has thus far focused on the critical rather than the creative and adding the word "creative" to the title better represents the importance it has. Critical thinking is not only about scrutinizing existing reasoning and argumentation, it is also about ingenuity, creation, and imagination.

Overall, the arguments presented here have suggested that imagination can help in, among other things, (1) constructing an audience (whether a single interlocutor, or community of model interlocutors, or universal audience), (2) determining which and how many reasons (argument schemes) to employ, (3) coming up with more and better answers to critical questions, (4) countering the availability bias by bringing to mind considerations not immediately available, and (5) countering the planning fallacy by imagining worst case, rather than best case, scenarios.

To conclude, we can now provide rough answers to the questions set out at the end of section two: 
Q: There is no doubt that an Other can fulfil this role, but can every Other do so?

A: No. There are a number of ways that an Other may end up agreeing with you or stay silent when they should not.

Q: If not, what might make one Other better or worse than another?

A: A key component is that the Other be critical-genuinely if possible, but even contrived dissent will help.

Q: Further, if an Other is helpful, would more than one Other be even more helpful?

A: Sometimes. Groups can help alleviate the availability bias and contribute with imagination, but if not worked with carefully, they can actually amplify individual errors.

Q: Finally, what are we to do if there is no Other around but a decision still has to be made?

A: Do your best to improve your critical creative capacity and address controllable biases that could negatively influence your reasoning and argumentation.

Acknowledgements: I am grateful to the anonymous referees of this article for their helpful comments. Funding was provided in part by the Fundação para a Ciência e a Tecnologia (Grant No. PTDC/MHC-FIL/05212014).

\section{References:}

Bailin, S. (1988). Achieving Extradordinary Ends: An Essay on Creativity. Dordrecht: Kluwer Academic Publications.

Bailin, S., \& Siegel, H. 2003. Critical thinking. In N. Blake, P. Smeyers, R. Smith, \& P. Standish (Eds.), The Blackwell Guide to Philosophy of Education (pp.181-193). Malden: Blackwell.

Baker, M., Rudd, R., \& Pomeroy, C. 2001. Relationship between critical and creative Thinking. Journal of Southern Agricultural Education Research, 51(1), 173-188. 
Baumtrog, M. D. 2013. Considering the role of values in practical reasoning argumentation evaluation. In $\mathrm{D}$. Mohammed, \& M. Lewiński (Ed.), Virtues of Argumentation. Proceedings of the 10th International Conference of the Ontario Society for the Study of Argumentation (OSSA). (pp. 1-16). Windsor: OSSA.

Blair, J. A. 1998. The limits of the dialogue model of argument. Argumentation, 12, 325-339.

Blair, J. A., \& Johnson, R. H. 1987. Argumentation as dialectical. Argumentation, 1, 41-56.

Blair, J. A., \& Johnson, R. H. 2009. Teaching the dog's breakfast: Some dangers and how to deal with them. $A P A$ Newsletter on Teaching Philosophy, 9. Retrieved from http://apaonline.org/?teaching_newsletter

Bondy, P. 2015. Virtues, evidence, and ad hominem arguments. Informal Logic, 35(4), 450-466.

Bratman, M. E. 1987. Intentions, Plans, and Practical Reason. Cambridge: Harvard University Press.

Bryne, R. M. (2005). The Rational Imagination: How People Creative Alternatives to Reality. Cambridge: MIT Press.

Chappell, Z. 2011. Justifying deliberative democracy: Are two heads always wiser than one? Contemporary Political Theory, 10(1), 78-101.

Chappell, Z. 2012. Deliberative Democracy: A Critical Introduction. New York: Palgrave Macmillan.

Creativity as a Virtue of Character. 2014. In E. S. Paul, \& S. B. Kaufman (Eds.), The Philosophy of Creativity (pp. 125-144). Oxford: Oxford University Press.

Dennett, D. C. 1978. Brainstorms: Philosophical Essays on Mind and Psychology. Montgomery: Bradford Books.

DiYanni, R. 2015. The pearson Guide to Critical and Creative Thinking. Boston: Pearson.

Ennis, R. H. 1989. Critical thinking and subject specificity: Clarification and needed research. Educational Researcher, 18(3), 4-10.

Ennis, R. H., \& Weir, E. 1985. The Ennis-Weir critical thinking essay test. Pacific Grove: Midwest Publications.

Ericsson, K. A., \& Simon, H. A. 1980. Verbal reports as data. Psychological Review, 87(3), 215-251.

Foos, P. W., \& Boon, D. 2008. Adult age differences in divergent thinking: It's Just a matter of time. Educational Gerontology, 34, 587-594. 
Fox, M. C., Ericsson, K. A., \& Best, R. 2011. Do procedures for verbal reporting of thinking have to be reactive? A metaanalysis and recommendations for best reporting methods. Psychological Bulletin, 137(2), 316-344.

Greco Morasso, S. 2013. Multivoiced decisions: A study of migrants' inner dialoge and its connection to social argumentation. Pragmatics \& Cognition, 21(1), 55-80.

Hughes, W. 2000. Critical Thinking: An Introduction to the Basic Skills (3rd ed.). Guelph: Broadview Press.

Hundleby, C. (2015, April 20). Database that breaks down textbook contents. Retrieved from Critical Thinking ${ }^{2}$ : https://docs.google.com/spreadsheets/d/1_S5OnmRMCWi3g XjXwdI21Hfu86YA4xcmn9Jlnsk8IlU/edit\#gid=0

van Eemeren, F. H. 2010. Strategic Maneuvering in Argumentative Discourse: Extending the pragma-dialectical theory of argumentation. Amsterdam: John Benjamins.

van Eemeren, F. H., \& Grootendorst, R. 2004. A Systematic Theory of Argumentation: The pragma-dialectical approach. Cambridge: Cambridge University Press.

Johnson, R. 2000. Manifest Rationality. Mahwah: Lawrence Erlbaum Associates.

Kahneman, D. 2011. Thinking Fast and Slow. New York: Farrar, Straus and Giroux.

Kenyon, T., \& Beaulac, G. 2014. Critical Thinking Education and Debiasing. Informal Logic, 34(4), 341-363.

Kieran, M. 2014. Creativity as a Virtue of Character. In E. S. Paul, \& S. B. Kaufman (Eds.), The Philosophy of Creativity: New Essays (pp. 125-144). Oxford: Oxford University Press.

Missett, T. C. (2012, May). The development of critical and creative thinking skills for $21^{\text {st }}$ century learning. University of Virginia: Dissertation.

Mizrahi, M. 2014. The problem of unconceived objections. Argumentation, 28, 425-436.

Paulus, P. B., \& Nijstad, B. A. (Eds.). 2003. Group Creativity: innovation Through Collaboration. Oxford: Oxford University Press.

Perelman, C. 1982. The Realm of Rhetoric. (W. Kluback, Trans.) Notre Dame: The University of Notre Dame Press.

Perelman, C., \& Olbrechts-Tyteca, L. 1969. The New Rhetoric. (J. Wilkinson, \& P. Weaver, Trans.) Notre Dame: University of Notre Dame Press.

Robinson, K. 2011. Out of Our Minds: Learning to be Creative. Chichester: Capstone Publishing. 
Ross, L., \& Anderson, C. A. 1982. Shortcomings in the attribution process: On the origins and maintenance of erroneous social assessments. In D. Kahneman, P. Slovic, \& A. Tversky (Eds.), Judgement under uncertainty: Heuristics and biases (pp. 129-152). Cambridge: Cambridge University Press.

Schulz-Hardt, S., Brodbeck, F. C., Mojzisch, A., Kerschreiter, R., \& Frey, D. 2006. Group decision making in hidden profile situations: Dissent as a facilitator for decision quality. Journal of Personality and Social Psychology, 9(6), 10801093.

Schulz-Hardt, S., Jochims, M., \& Frey, D. 2002. Productive conflict in group decision making: genuine and contrived dissent as strategies to counteract biased information seeking. Organizational Behavior and Human Decision Processes, 88, 563-586.

Siegel, H. 1988. Educating Reason: Rationality, Critical Thinking and Education. New York: Routledge.

Sunstein, C. R., \& Hastie, R. 2015. Wiser: Getting Beyond Groupthink to Make Groups Smarter. Boston: Harvard Business Review Press.

Tindale, C. W. 1999. Acts of Arguing: A Rhetorical Model of Argument. Albany: State University of New York.

Tindale, C. W. 2004. Rhetorical Argumentation: Principles of Theory and Practice. Thousand Oaks: Sage.

Tiruneh, D. T., Verburgh, A., \& Elen, J. 2014. Effectiveness of critical thinking instruction in higher education: A systematic review of intervention studies. Higher Education Studies, 4(1), 1-17.

Tversky, A., \& Kahneman, D. 1973. Availability: A heuristic for judging frequency and probability. Cognitive Psychology, 5, 207-232.

Tversky, A., \& Kahneman, D. 1974. Judgment under uncertainty: Heuristics and biases. Science New Series, 185(4157), 1124-1131.

Walton, D. 2010. Why fallacies appear to be better arguments than they are. Informal Logic, 30(2), 159-184.

Walton, D., Reed, C., \& Macagno, F. 2008. Argumentation Schemes. Cambridge: Cambridge University Press.

Weisberg, R. W. 1986. Creativity: Genius and Other Myths. New York: W. H. Freeman and Company.

Weston, A., \& Stoyles, B. 2010. Creativity for Critical Thinkers (Canadian Edition). Oxford: Oxford University Press. 